\title{
Hydrology and public health: linking human leptospirosis and local hydrological dynamics in Trinidad, West Indies
}

\author{
Maria Cecilia Vega-Corredor ${ }^{*}$ and Jacob Opadeyi
}

\begin{abstract}
Background: Human leptospirosis is currently one of the most widespread bacterial zoonoses and is the only epidemic-prone infection that can be transmitted directly from contaminated water. Transmission in humans is caused by direct or indirect contact with contaminated water, soil or infected urine, blood or tissue of carrier animals. Initial symptoms are similar with those suffered during influenza, dengue or viral hepatitis. As the disease progresses, internal organs can be compromised causing severe hemorrhages, organ failure and, potentially, death. Human leptospirosis is a growing global public health problem although, in endemic areas, it is considered a neglected disease. Hydrological factors, including rainfall and floods, have been frequently related to human leptospirosis. In the Caribbean, leptospirosis is endemic and it is a disease under surveillance. Based on confirmed cases, in Trinidad \& Tobago the average annual incidence of human leptospirosis ranges between 1.78 to 1.84 cases per 100,000 population.

Methods: In this paper, we used Geographical Information System (GIS) analysis and Geographically Weighted Poisson Regression (GWPR) for the development of ecological models, to assess the spatial variability in the relationships between local hydrological factors and human leptospirosis occurrence at the community level on the island of Trinidad. Five explanatory covariates were developed for the analysis: rainfall, river drainage density, proportion of soil with free drainage, proportion of soil with imperfect/impeded drainage, and a topographic wetness index.

Results: The GWPR model presented an improvement (AICC = 392.46; deviance $=583.36$ ) over the Global regression model (AICC $=595.52$; deviance $=381.78$ ), indicating spatial variability in the relationship of human leptospirosis and hydrological factors. Pseudo $t$-values of rainfall, imperfect/impeded drainage soil and the topographic wetness index showed high values $(|t|>1.96)$ indicating that local relationships with leptospirosis occurrence may be significant.
\end{abstract}

Conclusion: Results suggest that rainfall, imperfect/impeded drainage soil and topographic wetness index influence the local dynamics of human leptospirosis.

Keywords: Human leptospirosis; Zoonosis; Waterborne disease; Neglected disease; Geographically Weighted Poisson Regression; Spatial heterogeneity; Spatial analysis

\footnotetext{
* Correspondence: mariacvc@hotmail.com

Faculty of Engineering, Department of Geomatics Engineering and Land

Management, University of the West Indies, St Augustine, Trinidad and

Tobago
} 


\section{Background}

Human leptospirosis is a waterborne disease caused by spirochetes of the genus Leptospira. Currently, it is considered the most common widespread bacterial zoonosis and a growing worldwide public health problem (Adler \& de la Peña Monctezuma 2010; Levett 2001). Leptospirosis is a disease with a very complex ecology involving the bacteria, the animal reservoirs, humans and their surrounding environment. Pathogenic leptospires are transmitted to humans by direct or indirect contact with infected urine, blood or tissue of carrier animals or urine-contaminated water, soil or food (Bharti et al. 2003; World Health Organization 2003; Caribbean Epidemiology Center 1999). The sources of contamination are commonly rats, but domestic or wild animals also can be carriers of the pathogenic bacteria (Lau et al. 2010a). Leptospirosis is considered the only epidemic-prone infection that can be transmitted to humans directly from contaminated water, damp soil, crop vegetation or mud, through cuts, abrasions, mucous membranes or wet skin (Levett 2001; Watson et al. 2007). In the humid tropics and subtropics, where the disease has a high impact, climatic and environmental factors such as rainfall, floods, land cover and land cover change have been related to the occurrence of leptospirosis (Bharti et al. 2003; World Health Organization 2003; Lau et al. 2010b). Initially, leptospirosis symptoms can be similar to those caused by flu but, as the disease progresses, internal organs can be compromised causing severe hemorrhages (e.g.Weil's disease), organ failure and, potentially, death (Vinetz et al. 2005).

Outbreaks have been reported from many regions around the world, including: Italy, 1994, (Beniamino et al. 1987) Nicaragua, 1995 (Zaki \& Shieh 1996), Brazil, 1996 (Barcellos \& Sabroza 2001), Russian Federation, 1997 (Kalashnikov et al. 2003), Honduras, 1998 (Naranjo et al. 2008), India, 1997, 1999, 2002 (Vijayachari et al. 2003; Sehgal et al. 2002; Jena et al. 2004), Australia, 1999 (Smythe et al. 2002) Hawaii, 2004 (Gaynor et al. 2007), Guyana, 2005 (Dechet et al. 2012), the U.S., 2005 (Stern et al. 2010) and the Philippines, 2009 (Amilasan et al. 2009). Besides being associated to floods following heavy rains during the rainy season, or floods which occur in areas affected by either tropical cyclones or land use/ land cover changes (Vinetz et al. 2005; Mahajan \& Chlabra 2008), outbreaks have been reported after occupational or recreational activities related to water such as fishing, farming, canoeing, fresh water swimming or bathing (Keith 1996; Sanders et al. 1999; Sejvar et al. 2003; Segura et al. 2005; Vanasco et al. 2008). Leptospirosis affects rural and urban areas (including slum settlements) irrespectively, and avoiding exposure to the disease can be difficult for populations living nearby environmental sources of contamination, particularly those which are frequently affected by heavy rainfall and floods (Maciel et al. 2008).

Incidence rates range from 0.1 - 1 per 100,000 population per year in temperate zones and as high as $10-100$ per 100,000 population per year or more in the tropics (World Health Organization 2003). Even though it is distributed worldwide, human leptospirosis is considered a neglected disease (Michel et al. 2002; World Health Organization 2011). Often, the lack of awareness about the scope of this public health threat among populations at risk leads to underreporting and misdiagnosis of cases (World Health Organization 2003). Viral hepatitis, influenza, malaria and, in particular, dengue are the conditions with which leptospirosis is more frequently misdiagnosed. Furthermore, in less developed countries, it is poorly recognized and laboratory diagnosis is less likely to happen due to a lack of appropriate testing equipment or the difficulty in processing samples to completion (Adler \& de la Peña Monctezuma 2010; Lau et al. 2010a).

In the Caribbean, human leptospirosis is endemic and a disease under surveillance. Between 1980 and 2005 a total of 12,475 cases of were reported from all Caribbean countries, with 2,370 (19\%) of these corresponding to Trinidad \& Tobago. In the last few years, Jamaica and Guyana have been the countries reporting the majority of cases throughout the region (Caribbean Epidemiology Center 2009; Caribbean Epidemiology Center 2010; Caribbean Epidemiology Center 2011). In Trinidad \& Tobago, the average annual incidence rate reported is 1.84 per 100,000 population (Mohan et al. 2009). In this country the disease is considered underreported and awareness regarding its existence among the population is limited. Consequently, the public health importance attached to this zoonosis is low, particularly when compared to other conditions such dengue or dengue hemorrhagic fever (Mohan et al. 2009).

With a projected increase in the frequency of natural hazards related to severe weather, such as floods resulting from intense precipitation (De et al. 2005; Min et al. 2011), combined with increasing anthropogenic changes to the environment such as urbanization or the establishment of informal settlements, it is likely that new suitable environments for leptospirosis propagation will be opened (Vinetz et al. 2005), increasing the risk for people to contract the disease. Small island developing states such as Trinidad \& Tobago can be at particular risk: their small size, vulnerable ecosystems, limited natural and financial resources and inadequate infrastructure make these countries susceptible to the effects of natural disasters (Lau et al. 2010b) and, as a result, potentially suitable environments for leptospirosis transmission and propagation.

Much remains to be understood about the role of environmental factors (hydrological in particular) on 
leptospirosis dynamics and how these can vary from one location to another. There is a clear need for multidisciplinary studies to help to understand the complex ecology and epidemiology of this disease, as well as the different mechanisms of non-biomedical factors influencing its occurrence (World Health Organization 2003; Lau et al. 2010b; Wilcox \& Colwell 2005). In the last few decades, GIS analysis and spatial statistics have been more frequently used for the development of ecological analyses of diseases. This has allowed the introduction of new approaches towards more suitable ways to explore disease spatial patterns as well as the intricate dynamics of disease determinants (Waller \& Gotway 2004; Lau et al. 2012). In this paper, GIS analysis and Geographically Weighted Poisson Regression (GWPR) (Nakaya et al. 2005) were used for the development of ecological models to explore and analyze spatial variations in relationships between local hydrological factors and leptospirosis occurrence. Following previous research which has linked leptospirosis with hydrological events such as floods and heavy rainfall e.g. (Lau et al. 2010b; Barcellos \& Sabroza 2001; Gaynor et al. 2007; Dechet et al. 2012; Amilasan et al. 2009), we present a multidisciplinary approach towards the quantitative analysis, assessment, modeling and mapping of the risk of leptospirosis in Trinidad at the community level, as it relates to hydrological factors. We explored the existence of spatial variation in human leptospirosis patterns and the existence of spatial heterogeneity in its relationship with local hydrological factors. Thus, we tested the hypothesis that spatial heterogeneity exists in these relationships.

\section{Methods}

\section{Study site}

This study was developed in the island of Trinidad, the larger of the two main islands comprising the Republic of Trinidad \& Tobago (Figure 1). The country, an archipelago located in the south of the Caribbean region, is a geological extension of South America and comprises an area of $5,128 \mathrm{~km}^{2}$. Trinidad's nearest neighbor is Venezuela, $11 \mathrm{~km}$ away from the North West coast. The area of Trinidad is $4,828 \mathrm{~km}^{2}$, approximately $94 \%$ of the total area of the country. The north of the island is crossed west to east by a chain of mountains with their highest peak at $940 \mathrm{~m}$ above sea level, mostly covered by rainforest. In the central region, the terrain changes into plains and in the south into hillsides. The climate in Trinidad is considered as tropical marine with an average temperature of $31^{\circ} \mathrm{C}$ during the day. There are two characteristic seasons throughout the year: dry, during January to May and wet, from June to December, as illustrated by the mean monthly rainfall in Trinidad shown in Figure 2a. Trinidad is divided into 519 communities within 14 regional corporations and municipalities. In the 2000 census the island population was calculated as 1,208,282; in the 2011 census it was 1,267,145 (CSO 2012).

\section{Leptospirosis dataset}

Data of leptospirosis cases used in this study were obtained with the permission of the Trinidad \& Tobago Ministry of Health $(\mathrm{MoH})$, under condition to keep private all personal information contained in the files. All data were retrieved from the National Surveillance Unit (NSU) of the MoH. Two types of leptospirosis data cases are collected by the health authorities in Trinidad: (i) reported cases, which have been clinically diagnosed as being suspicious of leptospirosis; and (ii) confirmed cases which have been confirmed by laboratory testing. In the NSU archives, 1,545 reported cases were found between 2001 and 2008, and 250 confirmed leptospirosis cases from 1998 to 2008. In this paper, only confirmed cases (CC) were used for models development. From these data, annual incidence of leptospirosis (cases per 100,000 population) was calculated (Figure $2 \mathrm{~b}$ ) as well as the mean and standard deviation of monthly leptospirosis incidence

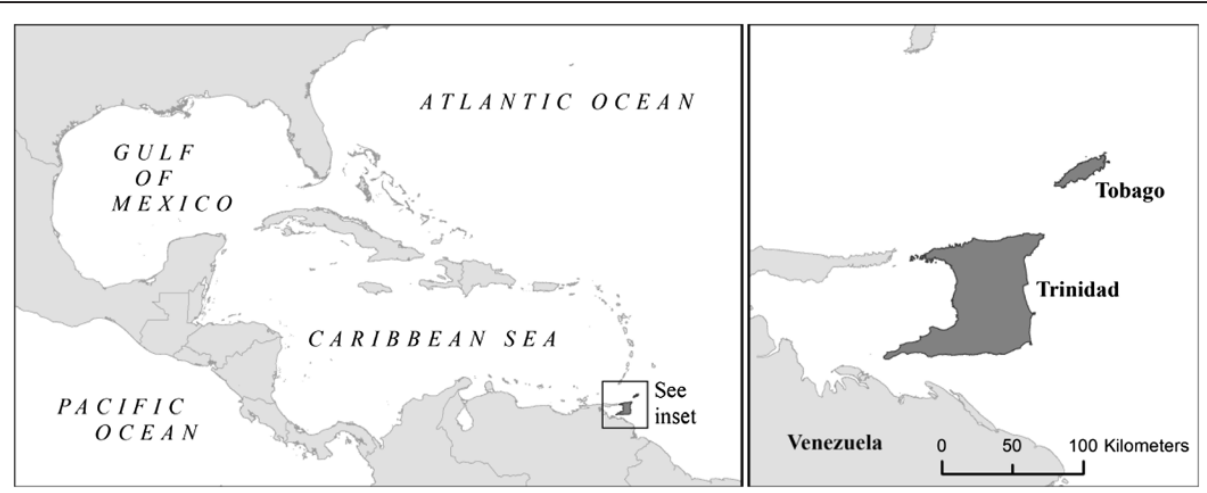

Figure 1 Geographical location of Trinidad and Tobago. 
(a)

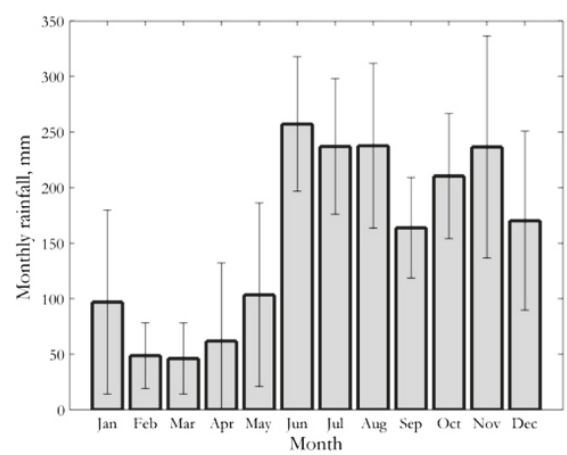

(c)

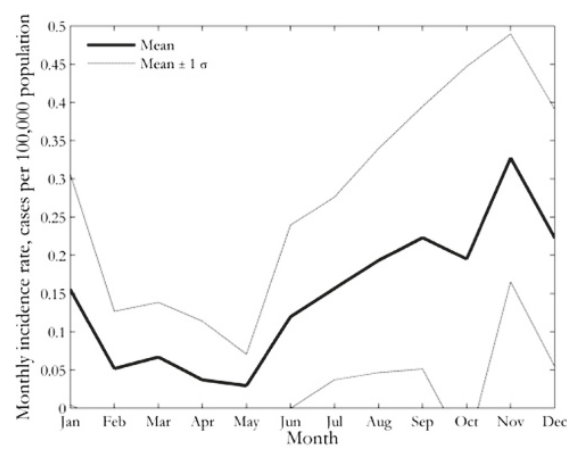

(b)

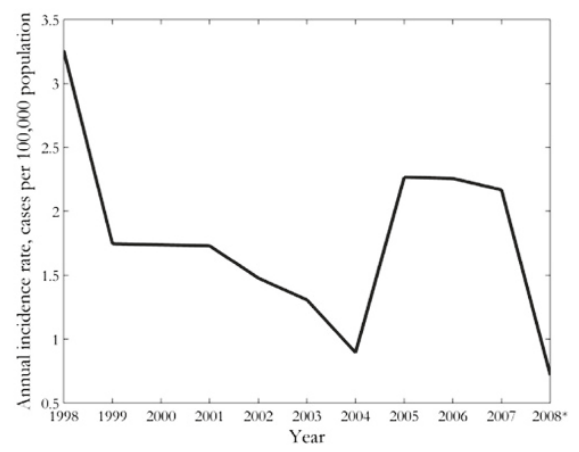

(d)

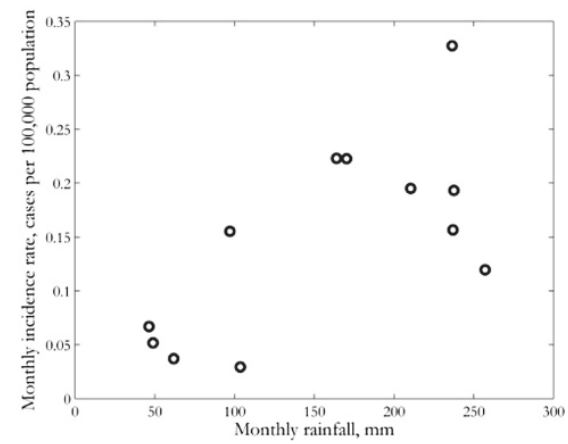

Figure 2 Summary of leptospirosis confirmed cases in Trinidad: (a) mean monthly rainfall in Trinidad, using data from the Piarco station, 1998-2008, provided by the Trinidad \& Tobago Meteorological Service (error bars indicate monthly standard deviation); (b) annual incidence rate from 1998 to 2008 produced using data from the Ministry of Health, Trinidad \& Tobago and annual population estimated from census data (CSO 2012) (*note that leptospirosis data for 2008 are incomplete); (c) mean monthly leptospirosis incidence rate for the same period; and (d) mean monthly rainfall vs. mean monthly leptospirosis incidence rate, indicating a weak positive correlation $\left(r^{2}=0.47\right.$, significant at the $95 \%$ confidence level) and seasonality in the relationship between leptospirosis and rainfall.

(Figure 2c). The relationship between monthly rainfall and incidence is shown in Figure 2d.

All CC records were digitized to a database and aggregated by community. The geographical location reported for each leptospirosis case (patient address and community) was verified within a GIS, using roads and communities vector data of the island. The community code number assigned to each community in the 2000 Trinidad Census was used to identify each community throughout the analysis. Community spatial centroids were used as the geographical coordinates for the models setup. All leptospirosis data from 1998 to 2008, aggregated by community, were mapped by absolute case number, as presented in Figure 3a.
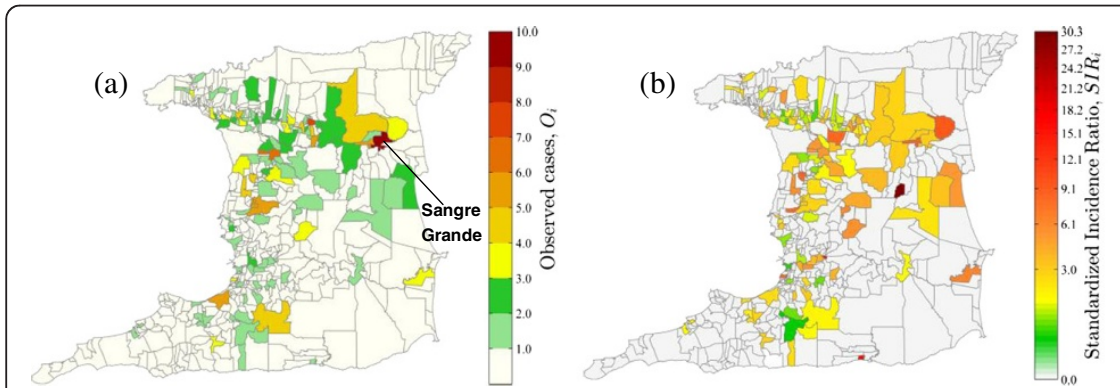

(c)

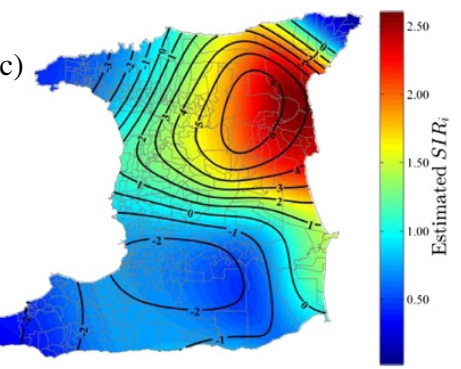

Figure 3 Distribution of leptospirosis confirmed cases in Trinidad, 1998-2008: (a) observed number of cases, $O$, for each of 520 communities, $i$; (b) Standardized Incidence Ratio $\left(S I R_{i}\right)$ for each community; (c) kernel map of estimated $S I R_{i}$, including pseudo $t$-values shown as contour lines. 
In order to compare leptospirosis incidence rates among communities, a standardized incidence ratio (SIR) (Jarup et al. 2002) in each community (i) was calculated by using:

$$
S I R_{i}=O_{i} / E_{i}
$$

where the expected number of leptospirosis cases $(E)$ by community $(i)$ was calculated by:

$$
E_{i}=\left(\frac{\sum_{i=1}^{n} O_{i}}{\sum_{i=1}^{n} P_{i}}\right) P_{i}
$$

Here, $P_{i}$ refers to the population of each of $n$ total communities, obtained from the Trinidad census of 2000. The expected number of cases $\left(E_{i}\right)$ was used to generate a kernel map and further Geographically Weighted Poisson Regression (GWPR) models.

\section{Kernel mapping}

We used kernel mapping (a special case of GWPR consisting of only a local intercept term without any explanatory variables) to investigate spatial patterns of observed vs. expected leptospirosis cases across the communities (Nakaya et al. 2005). This was necessary since underlying patterns of leptospirosis were not well defined at the community level due to the tendency of the number of cases to be small in some communities. Kernel mapping was used as an analogy to the geographical aggregation of data, a straightforward way to obtain statistically more reliable estimates of regional parameters (Nakaya et al. 2005). We obtained estimates of local leptospirosis weights using

$$
\exp \left(\hat{\beta}_{0}\left(\mathbf{u}_{i}\right)\right)=\left(\frac{\sum_{j}^{n} w_{i j} O_{j}}{\sum_{j}^{n} w_{i j} E_{j}}\right)
$$

where $\hat{\beta}_{0}$ is the predicted intercept parameter at geographical location, $\mathbf{u}_{i}$ (a vector of $x, y$ map co-ordinates, $\left.u_{x i}, u_{y i}\right)$, for community $i, w_{i j}$ are the geographical weights for the each $j$ predicted locations. Following Equation 3, local estimates of disease ratio were transformed into geographically weighted disease ratios. These ratios correspond to the ratio of the kernel density of observed leptospirosis CC to the kernel density of expected cases (Nakaya et al. 2005), and were used as a means to identify areas where leptospirosis cases were generally higher or lower than expected.

\section{Hydrological covariates development}

Although previous studies have extensively reported the association of leptospirosis with heavy rainfall and consequent floods (Lau et al. 2010b; Barcellos \& Sabroza 2001; Gaynor et al. 2007; Dechet et al. 2012; Vanasco et al. 2008; Mohan et al. 2009), in this study we focused the analysis on not only rainfall but also other hydrological factors that might play an important role in the disease occurrence. For this, a total of five hydrologically-related covariates were developed to be tested within GWPR models. For covariates selection, three main characteristics were taken into account: (i) capacity for development in GIS from data which are readily available and so easily replicated in other study locations; (ii) spatial variability (allowing mapping and spatial analysis); and (iii) representation of basin or watershed hydrological characteristics which have a clear potential to influence leptospirosis. Specifically, each selected covariate is an indicator of, or would influence, the general wetness of areas, thereby being a potential leptospirosis risk factor. For each community, average values of each covariate were calculated for comparison with leptospirosis data by community. The five covariates developed are described below. Specific data sources and processing methods used are provided in Table 1.

\section{Mean annual rainfall (RAINMEAN)}

In the tropics, as mentioned previously, leptospirosis has been strongly related to rainfall, including in a previous study for Trinidad (Mohan et al. 2009). Once severe rain or floods have occurred, the risk of leptospirosis increases since water brings into closer contact animal hosts, the bacteria and humans (Lau et al. 2010b). As one on the main hydrological factors associated with leptospirosis, rainfall was considered an important component for the GWPR model analysis. However, rather than only using a seasonal but spatially aggregated (global analysis) approach, in this study rainfall was combined with other hydrological factors as a way to explore the spatial nonstationarity of their relationships with leptospirosis at the community level. Although rainfall has been strongly associated with leptospirosis, high rainfall may not necessarily lead to an increase in leptospirosis risk, since other local factors may reduce or increase the risk, such as good or poor soil drainage, respectively. To develop the rainfall covariate, isohyetal maps of average annual rainfall across Trinidad were used. Relevant information related to the data source and processing methods used is presented in Table 1, and a map of mean annual total rainfall for each community is presented in Figure 4a.

\section{Soils drainage characteristics (SOILFREE and SOILIMPD)}

Composition of the soils and their drainage characteristics may be important factors which influence leptospirosis incidence. Previous studies have found association between pathogenic leptospirosis and soils with high moisture and organic matter content (Mohan et al. 2009; Henry \& Johnson 1978). Recently, it has been demonstrated that on dry days leptospires survive in wet 
Table 1 Summary of covariates, data sources and processing methods

\begin{tabular}{|c|c|c|c|}
\hline Covariate Identifier & Description & Data source & Processing methods \\
\hline \multirow[t]{3}{*}{ RAINMEAN } & \multirow[t]{3}{*}{$\begin{array}{l}\text { Community average annual } \\
\text { rainfall (mm/year) }\end{array}$} & \multirow{3}{*}{$\begin{array}{l}\text { Isohyetal maps of mean annual rainfall } \\
\text { in Trinidad from 1961-1990, 1991, 1999, } \\
\text { 2000, } 2001 \text { and } 2002 \text { (Trinidad \& Tobago } \\
\text { Meteorological Office). }\end{array}$} & $\begin{array}{l}\text { 1. Isohyetal maps georectified and digitized } \\
\text { to produce vector lines of equal mean } \\
\text { annual rainfall. }\end{array}$ \\
\hline & & & $\begin{array}{l}\text { 2. Vector lines were interpolated onto a } \\
\text { raster grid using a natural neighbor method } \\
\text { and the statistical mean across years was } \\
\text { then calculated using a weighted average. }\end{array}$ \\
\hline & & & $\begin{array}{l}\text { 3. Mean annual total rainfall for each } \\
\text { community was then extracted (Figure 4a). }\end{array}$ \\
\hline \multirow[t]{2}{*}{ SOILFREE, SOILIMPD } & \multirow[t]{2}{*}{$\begin{array}{l}\text { Proportion of soil with free } \\
\text { (SOILFREE) or imperfect/impeded } \\
\text { (SOILIMPD) drainage in each } \\
\text { community ( } \% \text { area) }\end{array}$} & \multirow[t]{2}{*}{$\begin{array}{l}\text { Trinidad 1:25,000 soils vector polygon } \\
\text { map and the land capability survey of } \\
\text { Trinidad \& Tobago (Brown \& Bally } \\
\text { 1970a; Brown \& Bally 1970b. }\end{array}$} & $\begin{array}{l}\text { 1. Codes of dominant soils in the island } \\
\text { were extracted from the soils map and, from } \\
\text { these, soil and drainage type were identified } \\
\text { (free draining, imperfect/impeded drainage). }\end{array}$ \\
\hline & & & $\begin{array}{l}\text { 2. Soils data were then intersected with } \\
\text { communities and the percentage area coverage } \\
\text { of free-drainage (Figure } 4 \text { b) and imperfect/ } \\
\text { impeded-drainage (Figure } 4 c \text { c) soils for each } \\
\text { community was calculated. }\end{array}$ \\
\hline \multirow[t]{3}{*}{ RIVRDENS } & \multirow[t]{3}{*}{$\begin{array}{l}\text { Average river density by } \\
\text { community }(\mathrm{m} / \mathrm{ha})\end{array}$} & \multirow[t]{3}{*}{$\begin{array}{l}1: 25,000 \text { vector line data of rivers in } \\
\text { Trinidad. }\end{array}$} & $\begin{array}{l}\text { 1. Using vector overlay, river vectors were split } \\
\text { at the community borders and assigned } \\
\text { community codes. }\end{array}$ \\
\hline & & & $\begin{array}{l}\text { 2. The vector length of each river segment was } \\
\text { calculated and the total length of the segments } \\
\text { was summarized by community. }\end{array}$ \\
\hline & & & $\begin{array}{l}\text { 3. Finally, the river drainage density for each } \\
\text { community (average river length per hectare) } \\
\text { was calculated by dividing the total river length } \\
\text { in each community by the community area } \\
\text { (Figure } 4 \text { d). }\end{array}$ \\
\hline \multirow[t]{3}{*}{ WETINDEX } & \multirow[t]{3}{*}{$\begin{array}{l}\text { Average wetness index by } \\
\text { community, } \ln \left(a / \tan S_{0}\right)\end{array}$} & \multirow{3}{*}{$\begin{array}{l}\text { Raster Digital Elevation Model (DEM) } \\
\text { derived from photogrammetry and } \\
\text { processed to remove topographic } \\
\text { "sinks". }\end{array}$} & $\begin{array}{l}\text { 1. Upslope flow accumulation }(a) \text { and local } \\
\text { topographic slope }\left(S_{0}\right) \text { in degrees were } \\
\text { calculated in GIS. }\end{array}$ \\
\hline & & & $\begin{array}{l}\text { 2. Wetness index was then derived for each pixel } \\
\text { using a map algebra calculation of } \operatorname{In}\left(\alpha / \tan S_{0}\right) \text {. }\end{array}$ \\
\hline & & & $\begin{array}{l}\text { 3. The average topographic wetness index for } \\
\text { each community was then extracted (Figure } 4 \mathrm{e} \text { ). }\end{array}$ \\
\hline
\end{tabular}

soils and then, on rainy days, they emerge into surface water (Saito et al. 2013). Based on this, soils may be considered to be a likely reservoir of leptospires in the environment and a relevant factor in the disease transmission. In addition, soil drainage can influence the likelihood of surface water ponding after rainfall. In this study, soil drainage data in Trinidad were analyzed (Table 1). Maps presenting percentage area of soil with free drainage (SOILFREE) and percentage area of soil with imperfect/impeded drainage (SOILIMPD) for each community are shown in Figure $4 \mathrm{~b}$ and c respectively.

\section{Average river density (RIVRDENS)}

Pathogenic leptospires have been found to be associated to water bodies such as streams, lakes or springs (Henry \& Johnson 1978) and it may be possible that areas with a high density of these features can be at higher risk of leptospirosis occurrence. In addition, high river density may indicate areas that are relatively wet thereby, areas at potential risk. Table 1 summarizes data and methods used to calculate river density in Trinidad for each community. Average river density for each community in Trinidad is presented in Figure 4d.

\section{Topographic wetness index (WETINDEX), In (a/tan $S_{0}$ )}

Rain and floods are considered two factors of risk for leptospirosis (Lau et al. 2010b; Barcellos \& Sabroza 2001; Vanasco et al. 2008). Therefore, the capability of an area to be flooded may be also a risk factor for the disease transmission. The topographic wetness index (TWI) identifies areas of increased likelihood of soil saturation, meaning areas more likely to be flooded. The TWI, developed by Beven and Kirkby to characterize the catchment contributing area for the hydrological rainfall-runoff model TOPMODEL (Beven \& Kirby 1979), was used here to represent the likelihood of community 


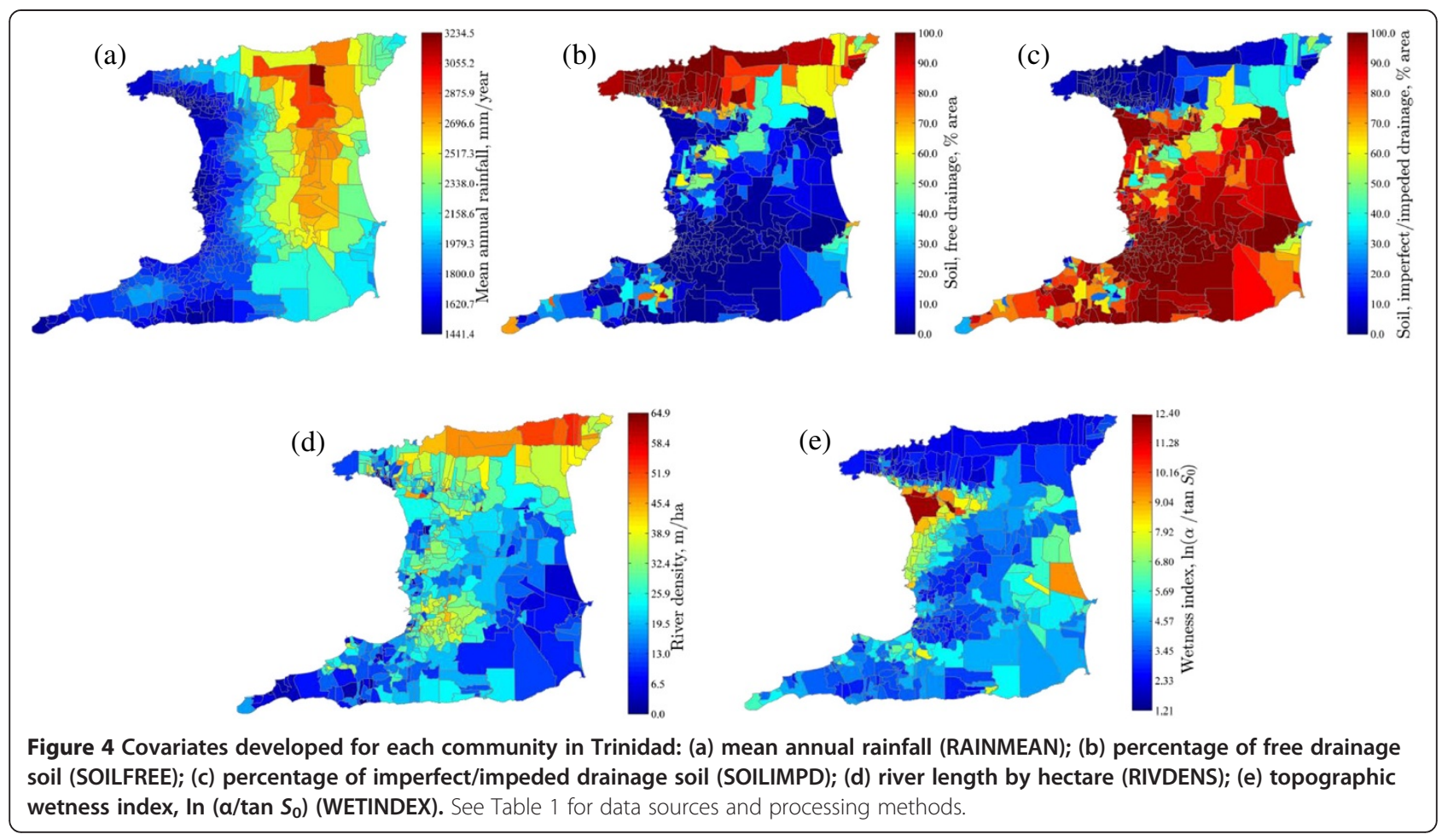

wetness. TWI is explored in detail by Cummingham et al. (Cummingham et al. 1970). The topographic wetness index was calculated using:

$$
\ln \left(\alpha / \tan S_{0}\right)
$$

where, $\alpha$ is the upslope flow accumulation and $S_{0}$ is the local topographic slope in degrees. A high wetness index exists where there is a combination of low slope and high flow accumulation (Beven \& Kirby 1979; Quinn et al. 1995), thus areas at greater likelihood for wetness are indicated. Methods used to obtain the parameters described above and, to calculate the topographic wetness index are explained in Table 1. The average topographic wetness index for each community calculated is presented in Figure 4e.

\section{Global Poisson Regression (GPR) and Geographically Weighted Poisson Regression (GWPR)}

In order to examine the spatial variation in the relationships between local hydrological factors and leptospirosis across the communities of Trinidad, non-parametric global Poisson regression (GPR) and Geographically Weighted Poisson Regression (GWPR) models were developed. GWPR methodology was adopted in accordance with the characteristic of the leptospirosis data which, due to the low numbers included in the observed counts, were expected to follow a Poisson distribution (Lovett \& Flowerdew 1989).
Prior to running GPR and GWPR models, a test for multicollinearity among covariates was developed using matrix condition numbers, within the spatial statistics toolbox of ArcGIS. Multicollinearity is a situation where two or more explanatory covariates are highly related linearly, and can lead to unreliable model estimates. The condition test assesses multicollinearity for all predictor variables together and assigns values to each location. Values above 30 are usually taken to indicate problems with the data.

For the development of the GPR and GWPR models, observed counts of leptospirosis confirmed cases were used as the dependent (outcome) covariate, with expected cases $\left(E_{i}\right)$ used as the offset variable. For independent (explanatory) covariates, average annual rainfall (RAINMEAN), the percentage coverage of free-draining soil (SOILFREE), the percentage coverage of imperfect/ impeded drainage soil (SOILIMPD), community river density (RIVRDENS) and the topographic wetness index (WETINDEX) were used, the development of each of which is explained previously.

Counts of leptospirosis CC were related to the calculated expected number of cases (offset covariate) and to the set of hydrological covariates developed for the model, and explained above. The global Poisson regression model was calibrated using

$$
O_{i} \sim \text { Poisson }\left[E_{i} \exp \left(\beta_{0}+\Sigma_{k} \beta_{k} x_{k, i}\right)\right]
$$


where $\beta_{0}$ refers to the model intercept and $\beta_{k}$ refers to the parameters of $k$ explanatory variables, $x_{k}$ in locations $i$. For Geographically Weighted Poisson Regression, parameters were allowed to vary in according to geographical location, $\mathbf{u}_{i}$, describing location $i$ :

$$
O_{i} \sim \text { Poisson }\left[E_{i} \exp \left(\sum_{k} \beta_{k i}\left(\mathbf{u}_{i}\right) x_{k i}\right)\right]
$$

To calibrate the GWPR models, kernel regression methodology was used. Smoothed geographical variations of parameters with spatial weighting kernels (centered in $\mathbf{u}_{i}$ ) were estimated and the parameter estimates calibrated in a point-wise way. To estimate GWPR parameters, the geographically weighted local likelihood principle was used (Lovett \& Flowerdew 1989). The key difference between GWR and a standard kernel regression model (SKRM) is that in GWR the kernel is in geographical space and the regression model is in predictorvariable space, while in SKRM both the regression model and the kernel are defined in predictor-variable space. GWPR software provides four different kernel types for the model calibration (fixed with a Gaussian weighting function, fixed bi-square, adaptive Gaussian and adaptive bi-square). In the fixed kernel, the optimal distance away from the regression point will be found; for adaptive, the optimal number of neighbors for use in the regression will be found. To avoid large standard errors and bias in local parameter estimates (due to either few data points in a short distance or a large number of points with a long distance to the regression point $i$ ) an optimal size of bandwidth is necessary (Cheng et al. 2011). In this study, the Akaike Information Criterion with a correction for finite sample sizes (AICc) (Fotheringham et al. 2002) was used as indicator to analyze the performance or goodness of fit of the models and the performance of the bandwidth, where the model with the minimum AICc value was selected as having the optimum bandwidth. The AICc together with a fixed Gaussian kernel type and golden selection bandwidth were the GWPR indicators used to complete model calibration. Full details of both the GPW and GWPR methods used are provided by Nakaya et al. (Nakaya et al. 2005).

All hydrological independent covariates were standardized to have a mean of zero and standard deviation of 1 , allowing parameter estimates to be directly comparable. Both GPR and GWPR were calibrating using GWR 4.0 Software. After model calibration, the pseudo $t$ statistic was calculated and used to assess local significance of parameter. The pseudo $t$ statistic was calculated using:

$$
t_{k}\left(\mathbf{u}_{i}\right)=\beta_{k}\left(\mathbf{u}_{\mathbf{i}}\right) / \operatorname{Se}\left(\beta_{k}\left(\mathbf{u}_{i}\right)\right)
$$

Where Se refers to the local standard error of the $k$ th parameter estimate, taking in account the variation in the data (Cheng et al. 2011). Pseudo t-values follow approximately a standard normal distribution if the true regression parameter is zero and mapping them is useful for identifying spatial variations in relationships between explanatory covariates and the outcome covariate.

To compare between models, the AICc was used. Generally, the model with the lowest value of AICc should be selected as the optimum model, but a difference of smaller than 2 suggest that there is little difference in the performance of the two models.

\section{Results and discussion}

\section{Distribution of leptospirosis in Trinidad}

The average annual incidence of leptospirosis between 1998 and 2008 calculated in this study was 1.78 per 100,000 population, slightly lower than the figure of 1.84 per thousand population calculated by Mohan et al. (Mohan et al. 2009). The reason for this reduction is probably related to the difference in the data time frame used in the studies: Mohan et al. (Mohan et al. 2009) analyzed data from 1996 to 2007, and here we analyzed data from 1998 to 2008. The annual incidence calculated in this study (Figure 2b) ranged from 0.69 in 2008 to 3.03 in 1998. However, the value for 2008 may be artificially low due to incomplete data for that year. With regard to seasonality, when comparing Figure $2 \mathrm{a}$ and $\mathrm{c}$ it is clear that a higher number of cases occurred during the wet season, although only a weak positive correlation between monthly rainfall and incidence was found $\left(r^{2}=\right.$ 0.47 , significant at the $95 \%$ confidence level) (Figure $2 \mathrm{~d}$ ). A likely cause of this weak relationship is the influence of other factors in leptospirosis occurrence.

When data were disaggregated to the community level, the community with highest number of observed CC found was Sangre Grande, the location of which is indicated on Figure 3a. Following Equation (1), the Standardized Incidence Ratio for each community $\left(S I R_{i}\right)$ was calculated and is mapped in Figure 3b. While there appears to be a general trend for higher numbers of leptospirosis cases in the north-east, the overall geographical pattern is not clear. As indicated above, this is likely to be because of the low numbers of cases in many communities. The kernel map in Figure $3 \mathrm{c}$ shows a smoothed geographical distribution of leptospirosis cases and facilitates the visualization of patterns across the communities. Low rates (below 1) are mostly seen in the south-west of the island; high rates (above 1) occur in the north-east and indicate areas where leptospirosis occurrence is higher than the average expected value given the community population size. The kernel map therefore allows us to infer that leptospirosis may present a geographically variable pattern with the highest incidence around the rural area of the Regional Corparation of Sangre Grande, including the communities Guaico, Valencia, Oropuche, Cumuto, Turure, Wallerfield and 
Arima. Further, the high pseudo $t$-values $(|t|>1.96)$ plotted as contour lines on Figure $3 c$ indicate that this pattern may be statistically significant, particularly in the north-east.

\section{GPR and GWPR model results}

Prior to the development of GPR and GWPR models, multicollinearity was assessed for all covariates. The condition numbers provided by the test results ranged from 19.25 in the central north communities to 27.88 in the far southwest ones. As all condition numbers were less than 30 , these results indicate that multicollinearity was not a problem among the covariates.

Following this test, a GPR model was developed using Equation (5) and calibrated as follows:

$$
\begin{aligned}
\hat{O}_{i}= & E_{i} \exp (-0.192+0.366[\text { RAINMEAN }] \\
& +0.125[\text { SOILFREE }] \\
& +0.032[\text { SOILIMPD }]-0.091 \text { [RIVRDENS }] \\
& +0.410[\text { WETINDEX] })
\end{aligned}
$$

where predicted leptospirosis cases $\left(\hat{O}_{i}\right)$ were related to the offset covariate $\left(E_{i}\right)$, expected cases of leptospirosis for each community and the five hydrological covariates developed. The full parameter estimates and corresponding $t$-values which indicate parameter significance are shown in Table 2. From all the covariates, two parameter estimates displayed statistical significance $(|t|>1.96$ at the $95 \%$ confidence level) in the GPR model: rainfall (RAINMEAN, $t=5.8$ ) and the topographic wetness index (WETINDEX, $t=6.2$ ). In both of these covariates, a positive relationship with leptospirosis was found, indicating that as rainfall increases, leptospirosis occurrence also increases. Similarly, as the topographic wetness index increases in a community, so the occurrence of leptospirosis also increases. The three remaining covariates showed weak relationships which were not statistically significant. However, these are general global relationships for Trinidad which may mask any underlying locally variable relationships. While global regression models are important for the study of disease

Table 2 Summary of global Poisson regression model parameter estimates and pseudo $t$-values statistics

\begin{tabular}{lcc}
\hline Covariate, $\boldsymbol{k}$ & Parameter estimate $\left(\boldsymbol{\beta}_{\boldsymbol{k}}\right)$ & $\boldsymbol{t}$-value $\left(\boldsymbol{\beta}_{\boldsymbol{k}} / \mathrm{Se}\left(\boldsymbol{\beta}_{\boldsymbol{k}}\right)\right)$ \\
\hline Intercept & -0.192 & -2.366 \\
RAINMEAN & 0.366 & 5.771 \\
SOILFREE & 0.125 & 0.797 \\
SOILIMPD & 0.032 & 0.195 \\
RIVRDENS & -0.091 & -1.050 \\
WETINDEX & 0.410 & 6.248 \\
\hline
\end{tabular}

Statistically significant covariates are indicated in bold type.
(Best et al. 2000), the assumption that the relationship between the disease and explanatory covariates does not vary spatially may not always be valid and a global model may hide local relationships. In such cases, it is important to consider the underlying spatial variability in order to avoid bias in the model outcomes.

In order to explore spatial variability between explanatory hydrological covariates and their influence on leptospirosis, a GWPR model was initially developed using all five hydrological covariates. This showed an improvement over the GPR model as indicated by the AICc and percentage deviance explained. When comparing the value of the AICc, the local model showed an improvement of 200 (GWPR: 395.77 compared to 595.52); the percentage deviance explained also showed improvement from 0.16 for the GPR model to 0.45 for the GWPR model (Table 3). In practice, if the difference between AICc values of two models is less or equal to two, there is no significant difference in the performance of them (Cheng et al. 2011). These values indicate that the GWPR model explains better the relationship between hydrological factors and leptospirosis by allowing these relationships to vary spatially. However, despite these improved measures, the results of the model calibration indicated the possible existence of inadequate inflation of the variance in the predictions, reducing the overall confidence in the GWPR model using all the covariates.

Next, a series of additional GWPR models were developed, in which all possible combinations of the five total hydrological covariates were used to explore the behavior of covariates on model performance (30 models in total, each with between 1 and 4 covariates). The model with the smallest AICc value (392.46) (Table 3, model 3), was selected as the model that better fitted the observed data. For model selection we followed the criteria of the minimum AIC estimator (MAICE) (i.e., the model with optimal bandwidth) where the model with the smallest AIC is selected (Nakaya et al. 2005; Jarup et al. 2002). The model selected included rainfall, topographic wetness index and the percentage of imperfect/ impeded soil and had an AICc value around 3 lower than the full GWPR model, indicating that there may be a substantive difference in the performance of the two models. In addition, the optimal bandwidth decreased from 42.8 to $33.1 \mathrm{~km}$. As bandwidth increases, a GWPR model is likely to tend towards the GPR model due to increased smoothing of weights given to data points. In addition, estimates may become biased due to the increasing distances of data from the regression point (Fotheringham et al. 2002). Conversely, for smaller bandwidths, parameter estimates will depend increasingly on observations in proximity to the regression point $i$, and their variance will increase (Charlton et al. 2005). This decrease in bandwidth, combined with an improved value for AICc, 
Table 3 Summary of global (GPR) and local (GWPR) models statistics for model comparisons

\begin{tabular}{|c|c|c|c|c|c|c|c|}
\hline \multirow[t]{2}{*}{ Model } & \multirow[t]{2}{*}{ GPR AICc } & \multirow[t]{2}{*}{ Bandwidth (km) } & \multirow[t]{2}{*}{ GWPR AICc } & \multirow[t]{2}{*}{ Deviance } & \multirow{2}{*}{$\begin{array}{l}\% \text { Deviance } \\
\text { explained }\end{array}$} & \multicolumn{2}{|c|}{ Diff of criterion } \\
\hline & & & & & & Par & Value(-) \\
\hline 1.Global PR & 595.52 & NA & NA & 583.36 & 0.16 & NA & \\
\hline 2.GWPR (all covariates)* & 595.52 & 42.8 & 395.77 & 380.99 & 0.45 & RAINMEAN & \\
\hline 3.WETINDEX, SOILIMPD, RAINMEAN & 592.68 & 33.1 & 392.46 & 381.78 & 0.45 & RAINMEAN SOILIMPD & $-0.053-0.247$ \\
\hline 4. WETINDEX, SOILIMPD & 637.57 & 18.4 & 401.04 & 384.23 & 0.46 & WETINDEX SOILIMPD & $-0.020-3.592$ \\
\hline 5. WETINDEX, SOILIMPD, RIVRDENS & 639.12 & 19.0 & 401.97 & 380.22 & 0.45 & SOILIMPD & -2.223 \\
\hline
\end{tabular}

* model results indicated that the variance of predictions may be inadequately inflated. Model was removed from consideration.

indicates a further divergence from the GPR model to one in which spatially variable relationships are important.

In model 3 (Table 3), two parameter estimates showed a negative value in the difference of criterion, indicating spatial variability: SOILIMPD $(-0.247)$ and RAINMEAN $(-0.053)$. In order to map the parameter estimates we calculated the standard odds ratio which showed the sensitivity of leptospirosis cases to a change of one standard deviation in each covariate as:

$$
\operatorname{Odds}_{k}\left(\mathbf{u}_{i}\right)=\exp \left(\beta_{k}\left(\mathbf{u}_{i}\right) \operatorname{SD}\left(x_{k}\right)\right)
$$

where $\mathrm{SD}\left(x_{k}\right)$ is the standard deviation of the $k$ th variable (in this case the covariates were standardized with mean zero and standard deviation 1). The patterns of the odds ratio calculated for each of the three parameter estimates are shown in Figure 5 together with pseudo $t$-values plotted as contour lines. In Figure $5 \mathrm{a}$, the odds ratio for rainfall (RAINMEAN) are all greater than 1.0, indicating that as the amount of rainfall in a community increases, leptospirosis cases also tend to increase. At the local level, all the pseudo $t$-values shown in this map were high, suggesting that the relationship between leptospirosis and rainfall is strong, particularly in the north-west region.

In Figure $5 \mathrm{~b}$ the majority of the odds ratios for soil with imperfect/impeded drainage are less than one, indicating that as the proportion of soil with imperfect/ impeded drainage increases, leptospirosis decreases, particularly in the south. Although this is counter-intuitive, the relationship as indicated by the pseudo $t$-values is very weak. As will be explored in further detail below, this may be due the influence of other covariates on the parameter estimates of soil with imperfect/impeded drainage.

In Figure $5 \mathrm{c}$ the odds ratio of the topographic wetness index are shown. As with the rainfall, all values of the odds ratios are above one, indicating that as wetness index increases, so does leptospirosis. Conversely to rainfall, however, the strongest relationship is in the south. Although the reasons for this trend are not clear, since rainfall tends to be lower in the south and west (Figure 4a), a possible explanation may be that the topographic wetness index is proportionally more important in these locations since it indicates the accumulation of water which is necessary for leptospires to survive in the environment. The pseudo $t$-values showed a strong relationship for all communities.

Figure 6 shows the predicted cases for each community $\left(\hat{O}_{i}\right)$ together with the residuals $\left(O_{i}-\hat{O}_{i}\right)$. Generally the predicted cases (range 0.006 to 10.45 , mean 0.422, variance 0.524 ) matched well the observed (range 0 to 10 , mean 0.422 , variance 1.144 ), with a root mean square error (RMSE) of 0.73 cases per community. Communities (a)

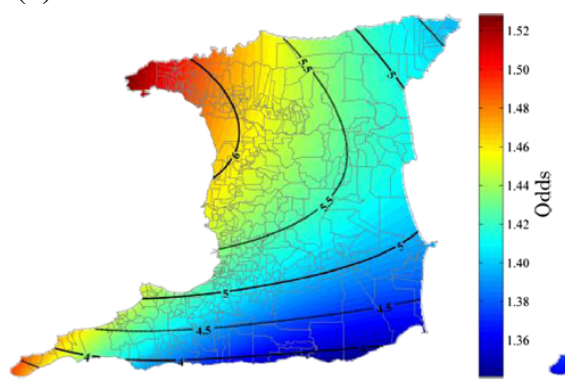

(b)

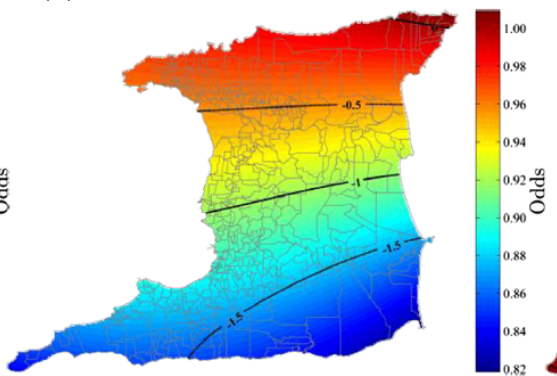

(c)

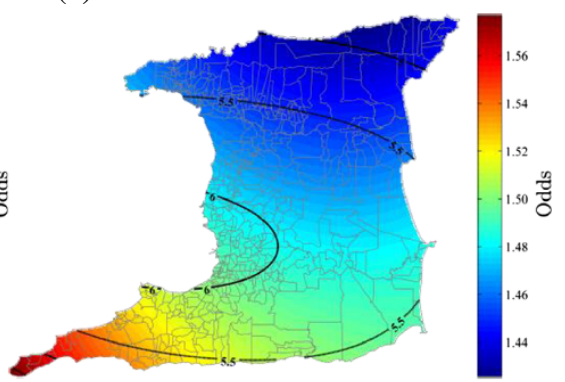

Figure 5 Optimum model parameter estimates (model 3, Table 3): standard odds ratio for (a) rainfall (RAINMEAN), (b) imperfect/ impeded drainage soil (SOILIMPD), and (c) topographic wetness index (WETINDEX). Pseudo $t$-values are shown as contour lines. 

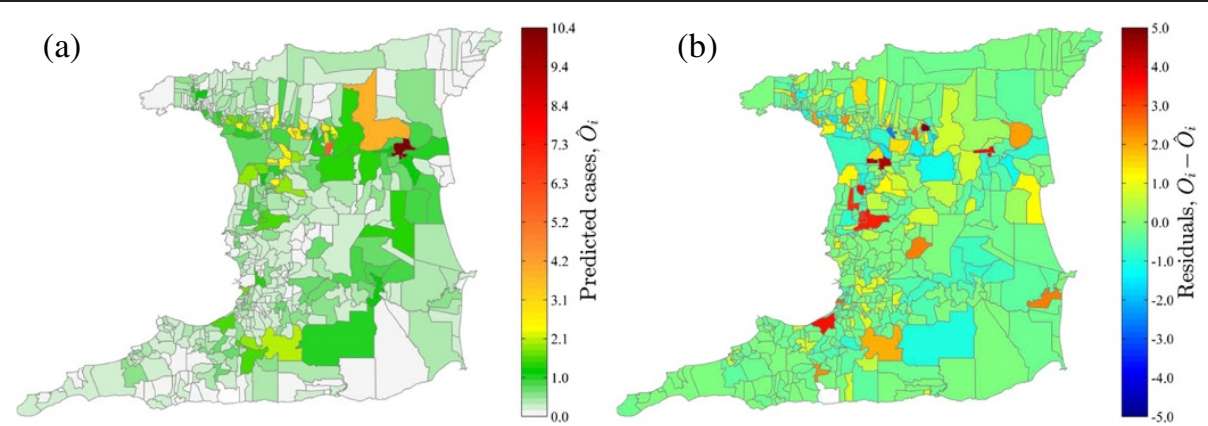

Figure 6 Model predictions by community: (a) predicted cases $\left(\hat{O}_{\mathrm{i}}\right) ;(b)$ residuals $\left(\mathrm{O}_{\mathrm{i}}-\hat{\mathrm{O}}_{\mathrm{i}}\right)$.

with a high number of cases such as Sangre Grande and neighboring areas were predicted accurately, as indicated by residual values close to zero. Predictions of leptospirosis were also made for communities which did not present confirmed cases in the data used for the analysis and, as would be expected, these communities were overpredicted. It is important to note that a lack of observations does not necessarily mean that there is no risk of leptospirosis. Rather, a lack of observations may be a result of underreporting or misdiagnosis of the disease, an issue described previously or simply that the length of the timeperiod under analysis is insufficient for all communities to have reported cases. Although more research is required, this suggests that models such as these may be useful tools to identify communities which may be at risk due to their environmental conditions, but which have yet to report cases.

Further analyses were developed to explore in more detail the underlying relationships between hydrological covariates and leptospirosis. For these, models that excluded rainfall as a covariate and presented high pseudo $t$-values in local parameter estimates were examined. Two models were selected for assessment (Figure 7). Although the AICc of these models increased in comparison to the values for the GWPR models described above, it was considered important to present their strong local variations related to leptospirosis. In Figure 7a, the local standard odds ratio for imperfect/ impeded drainage soil is presented for a model which included this covariate and the topographic wetness index (model 4 in Table 3). In contrast to Figure 5b, in the north side of the island, is showed a strong positive relationship between the percentage coverage of imperfect/ impeded drainage soil and leptospirosis occurrence, as indicated by the odds ratios above 1.0. The high pseudo $t$-values presented in the north indicate that this relationship may be significant. While the odds ratio in the south remains below 1.0, indicating a negative relationship, the pseudo $t$-values indicate that in this area this relationship remains weak. A similar situation occurred with the model presented in Figure $7 \mathrm{~b}$, for which the odds ratio for the topographic wetness index calculated in this model presented a positive and strong relationship, particularly towards the south. This is corroborated by the pseudo $t$-values which are high particularly in the central south region and remain high in most regions except the north east. In addition, the spatial variability in parameter estimates appeared to increase, leading to a (a)

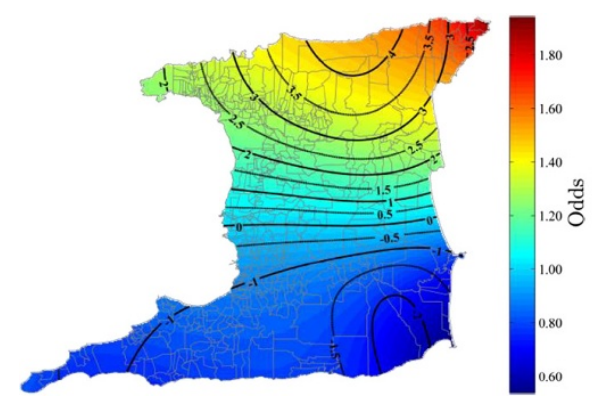

(b)

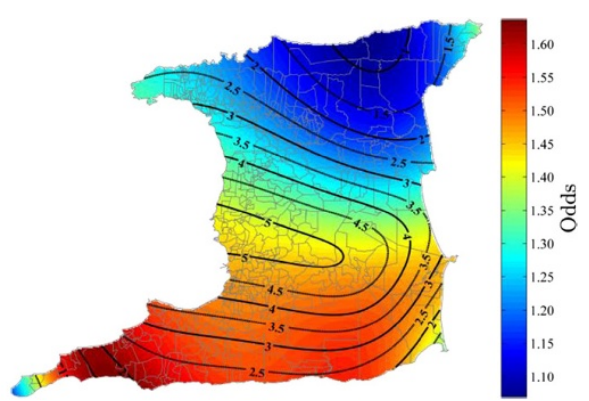

Figure 7 Model parameter estimates excluding rainfall (model 4, Table 3): standard odds ratio for (a) imperfect/impeded drainage soil (SOILIMPD) and (b) topographic wetness index (WETINDEX). Pseudo t-values are shown as contour lines. 
reduced optimal bandwidth of $18.4 \mathrm{~km}$ and indicating an increase in the importance of local relationships over global.

As described above, soil with imperfect/impeded drainage was not significant when rainfall was included as a covariate in the model, but once rainfall was removed from the model, the relationship in the north became locally significant. From this, we infer that soil with imperfect/impeded drainage may be a relevant factor for leptospirosis occurrence. Although the models showed that rainfall is clearly important to the occurrence of leptospirosis, when this covariate was not included in further models, the underlying relationships between other covariates and leptospirosis became clearer. In the statistical model, it appears that rainfall dominates the other, more localized effects of other hydrological covariates such as soil drainage and topographic wetness index, indicated by the reduction in the bandwidth observed when it was excluded and the increases in pseudo $t$-values. Soil drainage and wetness index are clearly local conditions which make the disease appear to be stronger in some communities. Using GWPR we were able to explore the spatial heterogeneity of human leptospirosis and its underlying related hydrological factors. This would not be possible using only global models, which do not account for this variability. In addition, global models which spatially average are contrary to the common purpose of disease studies which aim to identify important local clusters of disease occurrence (Fotheringham et al. 2002).

The results shown in the kernel map and predicted cases (Figures $3 \mathrm{c}$ and 6) presented a common pattern of expected and predicted leptospirosis risk for the north east of Trinidad, more specifically, for Sangre Grande and the surrounding communities. Parameter estimates for hydrological covariates such imperfect/impeded soil drainage and wetness index reveal interesting patterns towards the northern part of Trinidad (Figure 6). These results may suggest the existence of an important cluster of leptospirosis related to the local hydrology of this area which requires further and more detailed analysis. The findings regarding a possible cluster in the Sangre Grande surrounding area, a predominantly agricultural region, may also suggest that leptospirosis in Trinidad could be related to rural areas.

Although hydrologic factors are clearly influencing human leptospirosis in Trinidad, we must acknowledge the importance of other aspects such as socio-economic, demographic and additional environmental indicators and it is possible that these other factors may be confounders for the observed relationships, something which requires further investigation. The ecology of leptospirosis is highly complex and, in the attempt to contribute to its explanation in the Caribbean region, in this paper we only explored one important facet of it. In future work, the interaction among multiple types of covariates and their influence on human leptospirosis should be explored. To date, no similar modeling studies have been developed in the country.

\section{Conclusions}

Kernel mapping analysis allowed us to reveal the existence of geographical patterns of leptospirosis across Trinidad, where low rates (below 1) were found in the south-west communities and high rates (above 1) occurred in the north-east. The highest leptospirosis incidence was found in the rural area of the Regional Corparation of Sangre Grande, including the communities Guaico, Valencia, Oropuche, Cumuto, Turure, Wallerfield and Arima. To support these findings, pseudo $t$-values (Figure 3c) indicated that this pattern may be statistically significant, particularly in the north-east.

For the global analysis using GPR, rainfall (RAINMEAN) and the topographic wetness index (WETINDEX) were both found to be statistically significant $(|t|>1.96)$ at the $95 \%$ confidence level), with $t$ values of 5.8 and 6.2, respectively. However, since this was a global model, it did not help to understand if spatial variability exists in the relationship of leptospirosis and hydrological factors. Improvement of the local (GWPR) over the global (GPR) models results, indicated by AICc and percentage of deviance explained, suggests that GWPR models explained better the relationship between hydrological factors and leptospirosis. In practice, if the difference between AICc values of two models is less or equal to two, there is no significant difference in the performance of them (Cheng et al. 2011). In this way, the existence of spatial heterogeneity in the relationship was also demonstrated. The model which included rainfall, topographic wetness index and the percentage of soil with imperfect/ impeded drainage was selected as best fitting the observed data, from which we conclude that these three factors are to some extent important for leptospirosis throughout Trinidad communities. Odds ratio and pseudo $t$-values of these parameter estimates also demonstrated spatial heterogeneity across the island.

Stronger underlying local relationships were also revealed when rainfall was excluded from the model. Throughout the exploration of the data an interesting human leptospirosis cluster was found. Thus, GWPR was also used as a spatial analysis technique to reveal important underlying geographical patterns in the association of human leptospirosis with local hydrological dynamics (Nakaya et al. 2005).

Based on the accuracy of predictions obtained from the analysis of observed cases in each community $\left(\hat{O}_{i}\right)$ and the residuals $\left(O_{i}-\hat{O}_{i}\right)$ we can conclude that GWPR is useful as an exploratory tool for the identification of areas at risk as well as for the study of the risk of misdiagnosed, under reported, or neglected disease with a high environmental 
component, such as leptospirosis. While we acknowledge the multifactorial causes of leptospirosis, here we have used GWPR to indicate the important influence of local hydrological dynamics on human leptospirosis in Trinidad. However, it is important to note that ecological studies such as this one are not able to assign causation and, as such, more research is required to investigate the covariates identified as they relate to leptospirosis (e.g. using a case-control study). Additionally, seasonality in relationships should be assessed at a localized level. In this study it was not possible since insufficient data were available to allow the level of disaggregation required.

We hope that the research presented in this paper provides useful guidance for the development of more detailed studies. We took a multidisciplinary, integrated approach to the study of a disease of public health importance, strongly related to the environment. In order to find appropriate solutions to these issues, future research should consider a holistic approach for their study, looking at diseases associated with the environment as multifactorial problems rather than in isolation.

\section{Competing interests}

The authors declare that they have no competing interests.

\section{Authors' contributions}

MCV retrieved and systematized the disease data, developed the covariates within GIS, completed the model calibrations, statistical analysis and wrote the manuscript. JO participated in the design of the study and gave advice about the statistical frame work. All authors read and approved the final manuscript.

\section{Acknowledgments}

We would like to thank Dr Avery Hinds and all the members of the Surveillance Unit of the Ministry of Health of Trinidad \& Tobago for their help and support in gathering the Leptospirosis data. The software of GWR4 used in this paper is available at: http://gwr.nuim.ie/.

PhD research has been funded by a scholarship from the University of the West Indies. MCV would like to thank Dr Matthew Wilson for his constructive comments on drafts of the manuscript.

Responsible editor: Michael Piasecki

Received: 17 April 2013 Accepted: 28 November 2013

Published: 12 February 2014

\section{References}

Adler B, de la Peña Monctezuma A (2010) Leptospira and leptospirosis. Vet microbiol 140:287-296

Amilasan AT, Ujiie M, Suzuki M, Salva E, Belo MCP, Belo MCP, Koizumi N, Yoshimatsu K, Schmidt WP, Marte S, Dimaano EM, Villarama JB, Ariyos K (2009) Outbreak of Leptospirosis after Flood, the Philippines. Emerg Infect Dis 18:91-94

Barcellos C, Sabroza PC (2001) The place behind the case: leptospirosis risks and associated environmental conditions in a flood-related outbreak in Rio de Janeiro. Cad Saude Publica 17(Suppl):59-67

Beniamino C, Ciceroni L, Maffei C, Distanislao F, Strusi P, Calegari L, Lupidi R, Scalise G, Cagnoni G, Renga G (1987) A Waterborne Outbreak of Leptospirosis. Am J Epidemiol 126:535-545

Best N, Ickstant K, Wolpert R (2000) Spatial Poisson regression for health and exposure data measured at disparate resolutions. J Am Stat Assoc 95:1076-1088

Beven KJ, Kirby MJ (1979) A physically based, variable contributing area model of basin hydrology. Hydrolog Sci B 24:43-69
Bharti AR, Nally JE, Ricaldi JN, Matthias MA, Diaz MM, Lovett MA, Willing MR, Gotuzzo E, Vinetz JM (2003) Leptospirosis : a zoonotic disease of global importance. The Lancet Infect Dis 3:757-771

Brown CB, Bally GS (1970a) Land Capability Survey of Trinidad and Tobago No. 4: Soils of Central Trinidad. The Government of Trinidad and Tobago, The University of the West Indies, Texaco Oil Company, Shell Trinidad Limited, Tate and Lyle (Caroni Limited), British Petroleum (Trinidad) Limited, Trinidad, pp 1-142

Brown CB, Bally GS (1970b) Land Capability Survey of Trinidad and Tobago No. 5: Soils of Central Trinidad. The Government of Trinidad and Tobago, The University of the West Indies, Texaco Oil Company, Shell Trinidad Limited, Tate and Lyle (Caroni Limited), British Petroleum (Trinidad) Limited, Trinidad, pp 1-145

Caribbean Epidemiology Center (1999) A Caribbean Communicable Disease Surveillance Manual for Public Health Action. Caribbean Epidemiology Center, Trinidad

Caribbean Epidemiology Center (2009) Annual Report. Caribbean Epidemiology Center, Trinidad

Caribbean Epidemiology Center (2010) Annual Report. Caribbean Epidemiology Center, Trinidad

Caribbean Epidemiology Center (2011) Annual Report. Caribbean Epidemiology Center, Trinidad

Charlton M, Fortheringham S, Brunsdon C (2005) Geographically Weighted Regression, ESRC National Centre for Research Methods, NCRM Methods Review Papers 2005, NCRM/006. ESRC National Centre for Research Methods, University of Southampton, Southampton

Cheng EM, Atkinson PM, Shahani AK (2011) Elucidating the spatially varying relation between cervical cancer and socio-economic conditions in England. Int J Health Geogr 10:51

CSO (2012) Trinidad and Tobago 2011 Population and Housing Census Demographic Report. Central Statistical Office, Ministry of Planning and Development, Government of the Republic of Trinidad and Tobago [http:// www.cso.gov.tt/sites/default/files/content/images/census/TRINIDAD\%20AND \%20TOBAGO\%202011\%20Demographic\%20Report.pdf]

Cummingham RK, Vlitos AJ, Spector J, Brown CB (1970) Land Capability Survey of Trinidad and Tobago No. 5: Soils of Northem Trinidad. The Government of Trinidad and Tobago, The University of the West Indies, Texaco Oil Company, Shell Trinidad Limited, Tate and Lyle (Caroni Limited), British Petroleum (Trinidad) Limited, Trinidad, pp 1-140

De US, Dube RK, Prakasa Rao GS (2005) Extreme Weather Events over India in the last 100 years. J Ind Geophy. Un 9:173-187

Dechet AM, Parsons M, Rambaran M, Mohamed-Rambaran P, FlorendoCumbermack A, Persaud S, Baboolal S, Ari MD, Shadomy SV, Zaki SR, Paddock CD, Clark TA, Harris L, Lyon D, Mintz ED (2012) Leptospirosis Outbreak following Severe Flooding: A Rapid Assessment and Mass Prophylaxis Campaign: Guyana, January-February 2005. PLoS ONE 7:e39672

Fotheringham A, Brunsdon C, Charlton M (2002) Geographically weighted regression: the analysis of the spatially varying relationships. John Wiley \& Sons, Chichester

Gaynor K, Katz AR, Park SY, Nakata M, Clark TA, Effler PV (2007) Leptospirosis on Oahu: an outbreak associated with flooding of a university campus. Am J Trop Med Hyg 76:882-885

Henry RA, Johnson RC (1978) Distribution of the genus leptospira in soil and water. Appl Environ Microbiol 35:492-499

Jarup L, Best N, Toledano MB, Wakefield J, Elliott P (2002) Geographical epidemiology of prostate cancer in Great Britain. Int J Cancer 97:695-699

Jena AB, Mohanty KC, Devadasan N (2004) An outbreak of leptospirosis in Orissa, India: the importance of surveillance. Trop Med Int Health 9:1016-1021

Kalashnikov IA, Mezentsev VM, Mkrtchan MO, Grizhebovskii GM, Briukhanova GD (2003) Features of leptospirosis in the Krasnodar Territory. Zh Mikrobiol Epidemiol Immunobiol 6:68-71

Keith W (1996) Leptospirosis associated with outbreak of acute febrile illness and pulmonary haemorrhage, Nicaragua, 1995. Lancet 347:535-536

Lau C, Smythe L, Weinstein P (2010a) Leptospirosis: an emerging disease in travellers. Travel Med Infect Dis 8:33-39

Lau CL, Smythe LD, Craig SB, Weinstein P (2010b) Climate change, flooding, urbanisation and leptospirosis: fuelling the fire? Trans R Soc Trop Med Hyg 104:631-638

Lau CL, Clements AC, Skelly C, Dobson AJ, Smythe LD, Weinstein PS (2012) Leptospirosis in American Samoa - Estimating and Mapping Risk Using Environmental Data. PLoS Negl Trop Dis 6:e1669

Levett P (2001) Leptospirosis. Clin Microbiol Rev 14:296-326

Lovett A, Flowerdew R (1989) analysis of count data using Poisson regression. Prof Geogr 41:190-198 
Maciel EAP, de Carvalho ALF, Nascimento SF, de Matos RB, Gouveia EL, Reis MG, Ko Al (2008) Household Transmission of Leptospira Infection in Urban Slum Communities. PLoS Negl Trop Dis 2:e154

Mahajan S, Chlabra D (2008) Leptospirosis: A Re-emerging Disease. Vet World 1:182-185

Michel V, Branger C, Andre-Fontaine G (2002) Epidemiology of leptospirosis. Rev Cub Med Trop 54:7-10

Min SK, Zhang X, Zwiers FW, Heg GC (2011) Human contribution to more-intense precipitation extremes. Nature 470:378-381

Mohan ARM, Cumberbatch A, Adesiyun A, Chadee DD (2009) Epidemiology of human leptospirosis in Trinidad and Tobago, 1996-2007: a retrospective study. Acta tropica 112:260-265

Nakaya T, Fotheringham AS, Brunsdon C, Charlton M (2005) Geographically weighted Poisson regression for disease association mapping. Stat Med 24:2695-2717

Naranjo M, Suárez M, Fernández C, Amador N, González M, Batista N, González I, Valdez Y, Infante JF, Sierra G (2008) Study of a Leptospirosis Outbreak in Honduras Following Hurricane Mitch and Prophylactic Protection of the vaxSPIRAL ${ }^{\circledR}$ Vaccine. MEDICC Rev 10:38-42

Quinn PF, Beven KJ, Lamb R (1995) The $\ln (a / \tan \beta)$ index : how to calculate it a $n$ d how to use it within the topmodel framework. Hydrol Process 9:161-182

Saito M, Villanueva SYAM, Antara C, Miyahara S, Segawa T, Asoh T, Ozuru R, Gloriani NG Yanagihara Y, Yoshida S (2013) Comparative Analysis of Leptospira Strains Isolated from Environmental Soil and Water in the Philippines and Japan. Appl Environ Microbiol 79:601-609. 10.1128/AEM.02728-12

Sanders EJ, Rigau-Pérez JG, Smits HL, Deseda CC, Vorndam V, Aye T, Spiegel R, Weyant RS, Bragg SL (1999) Increase of leptospirosis in dengue-negative patients after a hurricane in Puerto Rico in 1996. Am J Trop Med Hyg 61:399-404

Segura ER, Ganoza CA, Campos K, Ricaldi JN, Torres S, Silva H, Céspedes MJ, Matthias MA, Swancutt MA, López Liñán R, Gotuzzo E, Guerra H, Gilman RH, Vinetz JM (2005) Clinical spectrum of pulmonary involvement in leptospirosis in a region of endemicity, with quantification of leptospiral burden. Clin Infect Dis 40(3):343-351

Sehgal SC, Sugunan AP, Vijayachari P (2002) Outbreak of leptospirosis after the cyclone in Orissa. Natl Med J India 15:22-23

Sejvar J, Bancroft E, Winthrop K, Bettinger J, Bajani M, Bragg S, Shutt K, Kaiser R, Marano N, Popovic T, Tappero J, Ashford D, Mascola L, Vugia D, Perkins B, Rosenstein N (2003) Leptospirosis in "Eco-Challenge"Athletes, Malaysian Borneo 2000. Emerg Infect Dis 9:702-707

Smythe L, Barnett L, Symonds M, Dohnt M, Baade P, McClintock C, et al. (2002) An outbreak of leptospirosis in North Queensland, Australia January to May, 1999. Technology 9:15-22

Stern EJ, Galloway R, Shadomy SV, Wannemuehler K, Atrubin D, Blackmore C, Wofford T, Wilkins PP, Ari MD, Harris L, Clark TA (2010) Outbreak of leptospirosis among Adventure Race participants in Florida, 2005. Clin Infect Dis 50:843-849

Vanasco NB, Schmeling MF, Lottersberger J, Costa F, Ko Al, Tarabla HD (2008) Clinical characteristics and risk factors of human leptospirosis in Argentina (1999-2005). Acta Trop 107:255-258

Vijayachari P, Sehgal SC, Goris MG, Terpstra WJ, Hartskeerl RA (2003) Leptospira interrogans serovar Valbuzzi: a cause of severe pulmonary haemorrhages in the Andaman Islands. J Med Microbiol 52:913-918

Vinetz JM, Wilcox BA, Aguirre A, Gollin LX, Katz AR, Fujioka RS, Maly K, Horwitz P, Chang H (2005) Beyond Disciplinary Boundaries: Leptospirosis as a Model of Incorporating Transdisciplinary Approaches to Understand Infectious Disease Emergence. Eco Health 2:291-306

Waller LA, Gotway CA (2004) Applied Spatial Statistics for Public Health Data. Wiley, New Jersey

Watson JT, Gayer M, Connolly MA (2007) Epidemics after natural disasters. Emerg Infect Dis 13:1-5

Wilcox B, Colwell RR (2005) Emerging and Reemerging Infectious Diseases: Biocomplexity as an Interdisciplinary Paradigm. Ecohealth 2:244-257

World Health Organization (2003) Human leptospirosis : Guidance for Diagnosis, Surveillance and Control. World Health Organization, Geneva

World Health Organization (2011) Report of the second meeting of the leptospirosis burden epidemiology reference group. World Health Organization, Geneva

Zaki SR, Shieh WJ (1996) Leptospirosis associated with outbreak of acute febrile illness and pulmonary haemorrhage, Nicaragua, 1995. Lancet 347:535-536 doi:10.1186/2194-6434-1-3

Cite this article as: Vega-Corredor and Opadeyi: Hydrology and public health: linking human leptospirosis and local hydrological dynamics in Trinidad, West Indies. Earth Perspectives 2014 1:3.

\section{Submit your manuscript to a SpringerOpen ${ }^{\circ}$ journal and benefit from:}

- Convenient online submission

- Rigorous peer review

- Immediate publication on acceptance

- Open access: articles freely available online

- High visibility within the field

- Retaining the copyright to your article

Submit your next manuscript at $>$ springeropen.com 